\title{
Mulher Rima com Dor? \\ Algumas considerações sobre a nação do prazer 'masculino' e do sofrimento 'feminino'
}

\author{
Woman Rhymes with Pain? \\ Some thoughts on the nation of 'male' pleasure and 'feminine' suffering
}

\author{
Verônica Daminelli Fernandes \\ Universidade Nova de Lisboa \\ veronica.daminelli@gmail.com
}

\begin{abstract}
Resumo
Este trabalho procura pensar o imaginário brasileiro que se apropriou do mito da mulher indígena para fundar não apenas o país enquanto território novo, mas também hierarquizou as mulheres dentro de um nacionalismo mitológico que impele a sexualidade 'feminina'. Simbolicamente reduzida aos olhos masculinos, a nativa indígena é metáfora da terra nova a ser desvirginada, possuída, nomeada e experimentada de acordo com os desejos masculinos, figurando como propriedade primitiva e erotizada. $\mathrm{Na}$ declarada pseudo-neutralidade das tradições do país do prazer, aquilo que queremos mostrar é a aceitação inconsciente das mulheres ao sofrimento artificial imposto, alinhando-se à uma 'natureza ideal da brasileira' que as essencializa no seu desejo de ser desejada custe o que custar.
\end{abstract}

Palavras-chave: Nacionalismo; mulheres; sofrimento; hierarquia de gêneros; Brasil.

\begin{abstract}
This paper tries to analyze the Brazilian imaginary that has appropriated the myth of indigenous women to found not only the country as a new territory, but also rank women according to a mythological nationalism that spurs women's sexuality. Symbolically reduced when regarded through male eyes, the native Indian is a metaphor for the new land to be deflowered, possessed, named and experienced in accordance with male wishes, figuring as a primitive and eroticized property. In the declared pseudo-neutrality of the traditions of the country of pleasure, what we want to show is women's unconscious acceptance of the artificial suffering imposed on them, allied with an 'ideal nature of the Brazilian woman' that sums up to their desire to be wanted at whatever cost.
\end{abstract}

Keywords: Nationalism; women; suffering; gender hierarchy; Brazil. 


\section{Introdução}

No primeiro trimestre de 2011, dois assuntos femininos pareceram mobilizar os cadernos e sites de cultura e de fofocas brasileiros. O primeiro foi $\mathrm{o}$ lançamento do filme 'Bruna Surfistinha' (Bruna Surfistinha; Marcos Baldini; 2011) com a atuação de Débora Secco como a prostituta que dá nome ao filme. O segundo, a transformação física de Cristiana Oliveira que engordou 15 quilos para viver a personagem Araci da nova novela das nove da Rede Globo, 'Insensato Coração'. Aqui, não pretendemos analisar o papel de cada uma em seus respectivos trabalhos, mas pensar a ligação sofrimento-amornacionalismo-gênero na cultura brasileira a partir da declaração que Cristiana fez ao afirmar que beleza, contrariando Vinícius, não era fundamental. Ao questionar "desde quando magreza é virtude (RISSATO, 2011)", Cristiana tocou no ponto exato da subjetividade 'feminina' que ainda hoje é definida na sua ligação com o belo, com a delicadeza e, nos tempos mais recentes, com a magreza. Se ao longo da história das mulheres, beleza e juventude se tornaram as características mais importantes quando se pensa numa mulher desejável, é compreensível que Cristiana tenha razão ao apontar o incômodo que perguntas como: 'Quantos anos você tem?' ou 'Quanto você pesa?' ainda causem nas mulheres da sociedade brasileira contemporânea.

De fato, a dita independência financeira feminina não acabou com o mito da feminilidade natural que definiu aquilo que, no espaço social, as mulheres devem ser/parecer. Muito longe disso, temos a exploração de imagens estereotipadas pela mídia que são usadas contra as mulheres em busca daquilo que seria uma feminilidade ideal (WOLF, 2002), pensando esta como qualidade estética em que as mulheres são produzidas, construídas e embelezadas para serem amadas, incapazes de escaparem da posição de mercadoria e, como diria Balzac no seu livro mais famoso, da condição de prostitutas. Nesse sentido, Bruna Surfistinha dialoga com aquilo que o autor de 'A mulher de Trinta Anos', muito tempo antes, já havia escrito ao abordar a dimensão histórica de uma França pós-Napoleão em que o amor e o casamento seriam, para as mulheres, uma prostituição pública, secreta e geradora de infelicidade e sofrimento (BALZAC, 1998, p.96). Para ele, seria pela beleza e pela virtude que as mulheres seriam escolhidas, cumprindo, com isso, uma lei da natureza que define o 'feminino' na sua busca pelo amor do homem. 'Bruna Surfistinha', trazendo a ligação para a contemporaneidade brasileira, apenas representaria de forma mais direta no cinema nacional aquilo que as mulheres não querem (ou conseguem) ver (encore, encore, encore), mas que os homens pagam com prazer: a submissão do desejo 'feminino' para a satisfação do consumo 'masculino' no mercado da atração sexual. Daqui, nem as mães de família escapam, como a Júlia de Balzac vai descobrir com sua vida cheia de sofrimentos, apesar de alinhada aos valores patriarcais. No império de troca que coloca as mulheres em posição de produtos e commodities em busca do reconhecimento do desejo e do amor de um homem, mais do que tempo, dinheiro, submissão e sexualidade, está em causa a sua dor (IRIGARAY, 2007).

Quando se fala de dor, fala-se não apenas daquela psicológica por não se poder ser o que se quer ser. Ou daquela de não ter palavras para expressar o que se sente como tão bem falou Clarice na sua busca por um coração mais selvagem, menos moldado pelos discursos definidores e normalizantes do que é 'ser mulher'. Não, não se trata da dor de se aceitar na passividade para ser amada ou de ter que se afirmar por valores patriarcais para se inserir na sociedade. Trata-se de um ser mulher inseparável do sofrimento físico que o ditado ocidental 'para ser bonita, tem que se sofrer' resumiria muito bem se trocássemos 'bonita' por 'amada'. Perda da virgindade, depilações, TPMs, cirurgias plásticas, dietas e, mais do que tudo, a maternidade. Aqui a biologia dissemina o imaginário de que as mulheres vêm ao mundo para sofrer e, por isso, podem resistir mais à dor e às dificuldades da vida (IRIGARAY, 2007, p.94-99). Como diria Irigaray (2007, p.95-96), é o trabalho de parto que introduz o 'feminino' como aquele que é capaz de sentir dor, sofrer, como uma afirmação da sua identidade. Os 
sacrifícios físicos pelo amor de um homem para resultar na dor de ser mãe são a condição básica do 'ser-mulher' na sociedade patriarcal-judaico-cristã na qual a cultura brasileira nacionalista também se fundou. $\mathrm{Na}$ verdade, o que queremos pensar é aquilo que Cristiana tentou colocar em debate quando questionou os sacrifícios pelos quais as mulheres - e, no caso, ela própria - têm que passar ao longo da vida para serem consideradas bonitas, desejadas, amadas e, além disso, aceitas enquanto imagem/representação do 'ser-mulher' no país do prazer. A sua declaração permite que debatamos a possibilidade do amor fora da padronização mecânica do sofrimento e da beleza femininos. E se, para ser amada, a mulher precisa ser objetificada, Cristiana parece perguntar: por que Bruna Surfistinha ainda nos choca tanto? Seríamos tão diferentes dela assim?

\section{As regras da atração e a sexualidade feminina}

Naquilo que veio constituir a erótica ocidental, desde Platão vivemos na bipolaridade que estabeleceu o tempo neutro e evolutivo, ou seja, o tempo dos homens, e o tempo cíclico das mulheres. Vivemos a mais tempo do que podemos imaginar nas dicotomias homem/mulher; razão/emoção; prazer/trabalho; corpo/alma. O mito do amor e do afeto também não fugiu à teoria platônica que fortaleceu na história da humanidade a busca pela metade da laranja, outra dicotomia (PLATÃO, s/d). Fala-se de amor como se falava a mais tempo do que podemos pensar. E nessa história da cultura ocidental, não apenas o sentimento mais importante adquiriu ares de 'natural', como se tornou o objetivo de vida da espécie humana (COSTA, 1998). Trazendo de volta à dicotomia, Luiz Felipe Pondé (2011, s/p), filósofo e professor da USP, reafirma que somos a única espécie que, para amar, enfrenta não apenas o ambiente externo, como o interno. Enquanto o primeiro seria o material, o físico, o do corpo; a alma ou o psiquismo seriam o espaço interno. Este, nas palavras dele, é aquele composto de experiências particulares como o afeto, o medo, as esperanças e as reflexões. No entanto, conforme ele questiona, é difícil refletir, resistir ou sentir fora da sociedade. Afinal, é pelo mundo externo que virão as leis nas quais estabeleceremos as manifestações da nossa alma, nossos pensamentos e o nosso espaço psicológico.

$\mathrm{Na}$ busca por aquele que nos vai trazer a felicidade completa, fala-se de amor, mas fala-se ainda de algo que é mais do que atração sexual, fala-se do corpo. Fala-se de um ambiente externo que vai operar toda a complexa rede de regras que por nós é interiorizada quando pensamos que estamos apaixonados (PONDÉ, 2011; ZIZEK, 2007; LACAN, 1975). Numa sociedade que impõe o amor e, então, as suas regras, amar é pertencer. Pertencer ao discurso dominante e ter os seus valores, os seus gestos, as suas roupas e o corpo que se deve ter. Tudo isso são processos de práticas coletivas que nos valorizam no mercado de afetos em que se busca o amor ideal. Para Lacan, um ato de comunicação, de vestir, comprar, o ato em sim mesmo é o consentimento reflexivo (reflexivo?) de que queremos estar naquela sociedade, de que assentimos aquela sociedade, mas não apenas compartilhando os seus valores, mas, de preferência, nos localizando no lugar mais alto da escala social (ZIZEK, 2007). Oscar Wilde tem razão: não devemos subestimar o poder da aparência. Romper com a cultura acerca do corpo é impedir as opções da alma numa sociedade em que tudo parece ser reflexo do capitalismo e das leis da economia (HOUELLEBECQ, 2009). A troca entre os seres humanos só é possível se estiverem dentro do pacto da linguagem, da imagem necessária a ser exposta aos outros de forma a ser desejada.

$\mathrm{Na}$ apresentação do eu na vida de todos os dias, não é possível uma alma descolonizada. Milan Kundera já sabia disso quando, n'A Insustentável Leveza do Ser', afirmou pela boca de Sabrina que nunca há intimidade real possível porque sempre estamos sendo observados, atuando com as nossas máscaras na ficção simbólica do espaço social (LACAN, 1975). Seríamos todos castrados, não só as mulheres, embora curiosamente a observação de Kundera seja dita pela boca de uma personagem feminina. Para Kundera ou Lacan, ninguém riria por último, ou melhor. Aquilo que causa o desejo, o afeto ou aquele 'je ne sais quoi' é mais do que sempre inseparável do bombardeamento de demandas acerca do corpo. A publicidade da nossa individualidade, da nossa unicidade e da nossa alma especial que vai ser reconhecida por uma troca de olhares como insistem em mostrar as propagandas da televisão está muito longe do campo do amor. Fora do corpo ideal, da beleza ideal, como amar?

De fato, poucos, provavelmente, são capazes de renunciar ao sistema de diferenciação que se baseia no sexo, no poder ou no liberalismo econômico quando escolhem o parceiro. O mercado de afetos é justamente onde o dinheiro se coloca de forma mais agressiva, em que 'o mais livre dos sentimentos' só se manifesta na ordem normalizadora do mundo (HOUELLEBECQ, 2009). Para se ter afeto, para se tocar a alma com o corpo, para se ter o contato físico do qual o amor também depende, a pele é a fronteira. Nada parece ser realizável no mercado das almas se estiver fora do 
mercado dos corpos, das aparências. É preciso de uma boa embalagem, do rosto certo, do corpo em forma, do estereótipo definido e definidor, para se manter na roda na qual o capitalismo, ou o amor, vai ser realizar. Conforme disse Nagel (2003, p. 51) em seu livro sobre gênero, etnicidade e nacionalismo, "the body is an instrument of performance and a site of performativity. Gender and sexuality are both performed and performative - conscious and unconscious, intended and unintended, explicit and implicit".

No entanto, se ambos os sexos estão dentro da dinâmica que define o corpo e a alma, Luce Irigaray lembra que ainda estamos muito longe de perceber os dois gêneros a partir da mesma ótica. No estado das relações em que os corpos e as almas (subjetividades) são trabalhados, ela mostra que a importância da beleza como valor de troca não é vivida da mesma forma por homens e mulheres. Enquanto, para os homens, a sua visibilidade no espaço público tem muito mais a ver com o seu poder aquisitivo e o seu status social, as mulheres continuam sendo aquelas que têm seu corpo a ser exibido, desejado e erotizado, experimentando a si próprias apenas quando correspondem às representações ideológicas definidas pelo masculino, seja na repetição do modelo profissional dos homens no mercado de trabalho ou na constituição da mulher enquanto esposa/dona de casa. De qualquer forma, nos dois lados da dicotomia, elas devem possuir uma feminilidade essencializada que as caracterize como mulheres. Nessa lógica, o corpo 'feminino' continua:

traditionally a use-value for man, an exchange value among men; in other others, a commodity. (...) Women are marked phallicly by their fathers, husbands, procurers. And this branding determines their value in sexual commerce. Woman is never anything but the locus of a more or less competitive exchance between two men (Irigaray, 1985, p.31).

Dessa forma, ainda que o movimento feminista tenha ajudado a acabar com a visão de uma essência do masculino e do feminino, ou seja, que não é mais possível falar de uma natureza d'A Mulher, já que esta não existe, o que Irigaray vai mostrar é que a condição feminina não deixou ainda de existir (SOLER, 2005, p.57). Não é por serem mulheres que elas acabam por se definir dentro do discurso da beleza e do sofrimento, mas, ao contrário, quando ali decidem se alinhar é que são chamadas e se reafirmam como mulheres pela sociedade e por si próprias (SOLLER, 2005; LACAN, 1975; ZIZEK, 2007). Conforme Lacan (1975) veio mostrar muito tempo depois, Freud já havia tocado na ferida ao evidenciar na psicanálise não como homens e mulheres vieram viver a sua vida sexual de formas diferentes, mas ao analisar de que forma eles se tornam homens e mulheres ('being human') justamente por se enquadrarem nos ideais comportamentais daquilo que é definido como 'ser-homem' e 'ser- mulher'. Lacan, dessa forma, toma consciência do humanismo e do big-Other simbólico criado ao redor do patriarcado, questionando a crença no discurso que faz o homem ser o centro da sua própria história e de si próprio (LACAN, 1975, p.4). No Freud que Lacan usa, nem o inconsciente e nem a sexualidade podem ser entendidas como fatos predados. Eles são construções, objetos com histórias, isto é, história do sujeito humano como um todo (os homens) e suas particularidades (as mulheres).

A partir desse ponto, Lacan tem o seu trabalho no sentido de reorganizar a psicanálise em busca de uma crítica da construção dos sujeitos humanos alienados das suas sexualidades. Aqui, ele não apenas fala do falo como marco que gerou a sexualidade heteronormativa naturalizada, mas fala da criação da diferença sexual em que o 'ser-mulher' deve ser entendido como construção arbitrária pelos poderes instituídos. A ausência e a inveja do pênis só passam a ter significado dentro da cultura e não em si próprios o que dá às mulheres a sua dimensão dentro do bigOther, ou seja, o seu espaço simbólico dentro da cultura (ROSE \& MITCHELL, 1985, p.17). O medo da castração só ganha significado ao se perceber, no social, as perdas que se podem enfrentar quando se questiona a ordem da cultura (ROSE \& MITCHELL, 1985, p.19). Lacan reafirma a construção de um desejo 'feminino' que é inseparável das construções acerca da subjetividade feminina, pensando esta como resultado de uma oposição ficcional em que o simbólico masculino deve completar o vazio simbólico das mulheres. Aqui, a 'mulher' é categoria que serve para garantir a unidade ao lado do homem, em que identidade e totalidade operam no nível da fantasia, embora, na fantasia social, seja a sexualidade 'feminina' aquela estabelecida pelo Outro, arbitrariamente fixada como faltante, inferior e sofredora, fechando para as mulheres a possibilidade de desejar na diferença. De fato, não há relação sexual possível.

Se a libido continua a ser unicamente masculina é natural que o acesso das mulheres ao mundo do trabalho deixe intactas as estruturas de poder que conduzem as suas vidas dentro da ordem falocêntrica. Uma mulher só se torna mulher quando se coloca dentro da ordem patriarcal do discurso. Para Wolf (2002, p.9-19), é a ideologia da beleza (e do 
sofrimento) o campo do patriarcado em que as ideologias feministas mais dificuldades têm em conseguir ultrapassar. O controle sobre o corpo da mulher "has grown stronger to take over the work of social coercion that myths about motherhood, domesticity, chastity, and passivity, no longer can manage (WOLF, 2002, p.11)." Beleza, então, está direta e explicitamente relacionada com sexualidade. Dessa forma, as mulheres devem incorporar aquilo que os homens querem possuir quando possuem uma mulher. Mulheres bonitas não apenas são disputadas por homens bem-sucedidos, mas também garantiriam uma reprodução mais bem sucedida. Aqui, o sistema de domínio masculino sobre o corpo das mulheres continua intacto e o mito da beleza não é sobre as mulheres, mas sobre as instituições masculinas e poderes institucionais (WOLF, 2002, p.11-13).

\section{A nação do prazer. Prazer de quem?}

Sobre o espaço público brasileiro, chama atenção o título da resenha da Revista Veja ('A nação do prazer) de 30 de março de 2011 sobre o novo livro da historiadora brasileira Mary Del Priore, 'Histórias Íntimas. Parecendo analisar superficialmente a obra da autora, a revista utiliza o box principal da reportagem para chamar atenção acerca das peculiaridades brasileiras que vão moldar no país uma libido que definiu a alma e o nacionalismo brasileiros desde o descobrimento até as 'mulheres-frutas' o que teria acabado por se tornar uma característica nacional específica e conhecida no mundo. O que a revista, porém, não fala é que o nacionalismo brasileiro defende e compartilha histórias de mitosrepresentações nacionais de aspectos morais, culturais e sociais que subordinou a sexualidade 'feminina' de uma forma que não pode ser subestimada. Na verdade, desde o colonialismo europeu, a história das representações femininas brasileiras parece ser a história do domínio sexual das mulheres. Conforme mostra Anne McClinton (1995, p.22-27), a América sempre foi considerada aquilo que ela denominou de 'porno-tropics' para a imaginação do homem europeu: um continente mágico para realização de desejos sexuais reprimidos pela civilização europeia Com a visão dos 'porno-tropics', "a world-knowloged dominated by Europe was animated not only by an imperial geography of power but also by a gendered erotics of knowledge (MCCLINTON, 1995, p.23)".

$\mathrm{Na}$ verdade, aquilo que McClinton parece querer dizer é que, em todos os países, os lugares das mulheres e dos homens não ocupam o mesmo espaço no imaginário simbólico nacional, o que significa também dizer que os gêneros não têm o mesmo espaço de igualdade naquilo que constitui uma nação e o seu nacionalismo, originando e definindo uma hierarquia dentro de cada comunidade. No caso do Brasil, a formação do seu nacionalismo parece ser inseparável das mitologias acerca do corpo objetificado e erotizado das mulheres nativas que, na representação literária, terá o seu ápice na criação da índia Iracema de José de Alencar. País virgem, primitivo, novo (características sempre associadas às mulheres), o imaginário do Brasil enquanto nação será inseparável da apropriação dos estereótipos das nativas locais, pensando estas como metáforas da nova terra a ser colonizada. Para McClinton (1995, p.23), a apropriação de um mundo desconhecido foi mapeado na história da Europa como uma 'metaphysics of gender violence', sendo validada pela lógica do Iluminismo que feminiliza o mundo como espaço a ser explorado. Essa feminilização da terra representa um momento do discurso imperial em que o masculino coloca como natural uma hierarquia de gênero dentro da cultura. De fato, na auto-invenção do Brasil, pensando o contexto de nação a partir da expressão 'imagined communities' de Benedict Anderson, o imaginário nacional foi simbolicamente construído a partir dos dramas/sofrimentos das mulheres relegadas a papéis secundários, mães $\mathrm{e}$ reprodutoras de filhos e do país, subordinando o 'feminino' ao domínio da tradição nacional-masculina, esta responsável por civilizar e lutar pela grandeza do Brasil. A microcultura do cotidiano, assim, se articula muito bem com as demandas do nacionalismo em que a cultura de gênero para homens e mulheres, meninos e meninas, é uma cultura de dominação masculina sobre o simbólico nacional.

A partir do simbolismo do descobrimento do Brasil enquanto terra virgem a ser colonizada, o mito da mulher indígena/nativa/brasileira pode ser entendido a partir de um imaginário que separou os interesses das mulheres dos interesses da nação. As índias são aquelas que já estavam na terra para atenderem ao desejo dos homens, tendo a sua nudez e o seu primitivismo erotizados pelos valores masculinos europeus civilizados. Iracema, mito/representação indianista principal da história literária do Brasil, ainda que seja uma índia especial porque virgem, será justamente por isso representação autêntica da terra descoberta a ser controlada na sua origem. Na espera passiva pela inseminação literal, ela é simbolismo de um desejo que quer ser apropriado pelo simbólico, pela razão moderna e pela linguagem (MCCLINTON, 1995, p.30). Em busca da colonização pelo patrimônio masculino, ela é "assured as the sexual and military insemination of an interior void (MCCLINTON, 1995, p.30)". Pura, nova, heterossexual por natureza, ela está fechada na conexão com a família e a comunidade. Ela 
é a encarnação dos interesses nacionais por duas razões: é a mãe dos filhos do marido e, depois, passa a encarar a honra nacional e masculina (NAGEL, 2003, p.162). A mulher aqui é:

an infinitive untrodden territory of desire which at every stage of historical deterritorialization, men in search of material for utopias have inundated with their desires. Women's sexuality is of futher concern to nationalism around the world because, as wives, sisters, mothers, and daughttersm women often are considered to be the bearers and incarnations of national and masculine honor (NAGEL, 2003, p.162).

A brasileira nativa é, assim, simbolicamente erotizada e reduzida aos olhos masculinos, tornando-se metáfora do Brasil enquanto país que se constrói a partir de um estereótipo feminino nacional: terra nova a ser desvirginada, possuída, nomeada, experimentada de acordo com os desejos masculinos, figurando como propriedade e objeto que pertence ao homem, fora do poder político.

Por outro lado, conforme Alencar faz ver no seu romance, se Iracema é a índia virgem a ser desejada como encarnação honrada da nação, ao seu redor, compartilhando o outro lado da mesma moeda, teremos as índias comuns que se oferecem, uma espécie de 'mulheres frutas' mais vanguardistas brasileiras que são definidas como aquelas que seduzem, convidam e corrompem os homens, insinuando sexo e submissão (MCCLINTON, 1995, p. 26) de forma recreacional. Serão as acepções como impureza, inferioridade ou hipersexualidade da brasileira como 'outro' baseado no mito da índia nativa que, muitas vezes, vai justificar uma atitude de servidão sexual e da imagem feminina ligada a propósitos eróticos. Ao organizar o imaginário nacionalista, o Brasil apropriou-se do mito indígena 'feminino' - embora ironicamente não dando aos índios valor na hierarquia social - de forma objetificada, criando um imaginário cultural e social sempre à disposição do homem e que ainda atualmente parece estar presente na sociedade contemporânea. As brasileiras, como as índias nativas, parecem ser muitas vezes aquelas que cordial e docilmente aceitam ocupar os seus espaços como seres desterritorializados, cujas sexualidades estão ao dispor do homem, reafirmando a liderança masculina e a importância de satisfazer o prazer do colonizador. Mais do que isso, não questiona a sua apropriação, aceitando-se na visão falocêntrica definida pelo colonizador que as sexualizou nas cartas, na literatura, nas pinturas e, atualmente, na mídia nacional. A representação mitológica da 'brasileira', então, se torna aquela de uma mulher aberta, cooperativa, mas, ao mesmo tempo, também 'Sodoma e Gomorra', promíscua, libidinosa, que se prostitui por qualquer valor, aquela que não perde a oportunidade de fazer sexo com qualquer um localizado na escala superior da esfera social e econômica (NAGEL, 2003, p.65). Os homens, por sua vez, serão aqueles dominados pela atração erótica e que correspondem à representação, não podendo resistir as nativas porque estas são atraentes, generosas, atiradas demais, vendendo-se por qualquer valor (NAGEL, 2003, p.6566). Aqui, a crença de uma sexualidade 'feminina' que é tão ou mais poderosa que o mais forte e resistente dos homens parece ter sido sempre utilizada na mitologia para justificar o estupro como responsabilidade e desejo da própria mulher (NAGEL, 2003, p.103). Dentro do imaginário em torno da brasileira hipersexualizada, as mulheres sofrem não apenas pela culpa do seu 'abuso sexual', como têm que arcar com as consequências da imagem que 'possuem'.

Se tal representação feminina na construção do nacionalismo do Brasil combina fatores que dizem respeito à sexualização e sensualidade 'banal' e 'natural' das brasileiras, ela também surge com o discurso do colonizador europeu como retrato de uma natureza 'moral' e 'cultural' inferior das sociedades outras que não as europeias (NAGEL, 2003, p.67). No entanto, o problema agrava-se quando tal imaginário/mitologia está presente também na relação interna do país, na hierarquia de gêneros do discurso nacional, em que a mulher deve exercer o seu papel enquanto imagem de pureza, virgindade e castidade por um lado e, por outro, promíscua, sedutora, corrupta dos valores morais, mais uma índia/nativa para consumo imediato. De qualquer forma, os dois lados do mesmo imaginário falam simbolicamente sempre da satisfação do colonizador masculino a partir da beleza de caráter 'único' e 'natural' da 'mulher brasileira', exótica, simpática, bonita, desejável. Nesse sentido, é compreensível que as mulheres-frutas ganhem tanto espaço na produção midiática brasileira atual. Faz sentido que Carolinas Dickemans declarem que passam fome para emagrecer, chegando a tomar apenas um prato de sopa por dia. Faz sentido que Claudia Liz quase tenha morrido na mesa de operação quando fazia uma lipoaspiração. Faz sentido que Xuxa volte a usar espartilho quase aos 50 anos. Faz sentido que mulheres queimem os seus couros cabeludos para terem o cabelo liso, certo e desejável. Faz sentido que Sandy seja, no meio delas todas, a Iracema contemporânea com quem os homens querem casar. Porém, mais do que isso, é 'compreensível' que a 
indústria turística do Brasil ainda promova o país com as suas ofertas sexuais como parte de uma nação que conta com 'recursos naturais', ainda não civilizados, recursos a serem apropriados pelo turista masculino (NAGEL, 2003, p.202-203) baseado na sexualidade e na beleza das suas mulheres locais. A beleza, assim, está definida para satisfazer a hierarquia de valores que, quando não satisfeitos, insistem na autodesvalorização feminina. Daí, a luta por um corpo ideal ser a solução. E, aqui, não faltarão oportunidades para a dor. É no sacrifício - que ironicamente nada tem de natural - feito para ter o poder de seduzir que as mulheres disputam seu espaço público colocando em risco sua saúde, sua subjetividade e seu papel político social. Sua autoafirmação como objeto a ser consumido/desejado reforça as acepções do masculino no discurso, nas imagens, na ação e, principalmente, no uso comercial do self feminino (IRIGARAY, 2007, p.94) dentro da cultura brasileira.

\section{No meu peito, bate um coração que chora}

Para Irigaray (2007, p.95), o sofrimento natural das experiências femininas durante a hora de parto tem sido inseparáveis das justificativas e imposições acerca da natureza 'feminina' como realidade de sofrimento inerente às mulheres. Para ela, tornar-se mulher sempre esteve relacionado com a dor, conforme Naomi Woolf (2002, p.219) vai explicar:

From the beginning of their history until just before the 1960s, women's gender caused them pain. Because of puerperal fever and childbed complications, giving birth was cruelly painful until the inventation of the chloroform in 1860, and moratally dangerous until the advent of antisepsis in the $1880 \mathrm{~s}$. Afterward, sex still carried the risk of illegal abortion, with its dangers of hemorrhage, perforated uterus, and death by blood poisoning. 'Labor' for women has meant childbirht, so that work, sex, alove, pain and death, over the centuries, intertwined into a living knot at the center of female consciousness: Love hurts, sex could kill a woman's painful labor was a labor of love.

Woolf (2002, p.218-220) vai dizer que apenas com o advento da pílula, a mulher começou a poder nos anos 60 a aproveitar o sexo sem os medos que anteriormente viriam com ele. Pela primeira vez, sexo e dor estavam separados. E, na estranha ausência da dor feminina, o mito da beleza entrou em circulação. Segundo ela, nenhuma geração pode falar da feminilidade sem relacioná-la à dor. E, na atualidade, o que machucaria seriam os imperativos da beleza que as mulheres aceitariam sem questionar. Estando historicamente acostumadas ao sofrimento, elas acolheriam com naturalidade e silêncio os sacrifícios que têm que fazer na busca (WOOLF, 2002, p.219) do corpo e da imagem (imaginário) ideal para se fazerem desejar, conscientes de que sofrimento gera beleza e beleza gera o amor. De fato, voltamos para aquilo que Irigaray apontou ao questionar como e quando podemos separar o tornar-se mulher do conceito de sofrimento, diferenciando a dor natural do parto, dos sofrimentos artificiais que a sociedade impõe aos corpos femininos (IRIGARAY, 2007, p.95). Como quebrar a identificação que diz que para ser mulher é preciso sofrer?

Mais do que romper com a ideia de erotismo a partir da visão padronizada e falocêntrica acerca do amor, aquilo que parece ser preciso é uma revisão das representações femininas nacionais tradicionais e contemporâneas capazes de questionar como a 'mulher brasileira' teve o seu gênero interpelado pelas criações nacionalistas que legitimam a sexualidade 'feminina' como objeto a ser definido pelo homem para o seu consumo. Assim como Iracema e as índias das aldeias formaram a ideia de objeto a ser possuído, hoje temos Déboras Seccos e Adrianes Galisteus a formarem o imaginário da mulher nacional divulgando os seus sacrifícios e sofrimentos para manter o 'corpo ideal'. $\mathrm{Ou}$ quantos meses de sofrimento a mesma Débora Secco, Xuxas, Ivetes e Taís Araujo confessaram passar para colocar próteses de silicone, ficando em torno de 5 meses sem poder dormir de bruços? Neste caso, trata-se ainda não apenas de estética, mas de colocar em risco a saúde e a própria sexualidade femininas.

Segundo Woolf (2002, p.242), qualquer cirurgia no seio pode gerar uma adversidade capaz de afetar a estimulação erótica da mulher, causando, assim, uma espécie de mutilação. Conforme ela pergunta, quem consegue imaginar implantes em pênis sendo incentivados em plena televisão? Ou pensar na capa de Caras e suas afins com declarações de injeção de silicone nos testículos ou qualquer coisa do gênero que diminua o sexual feeling masculino? Ou, mais ainda, que sociedade é essa que critica a mutilação clitoriana das mulheres ao redor do mundo, ao mesmo tempo em que aceita e incentiva o sofrimento das suas próprias mulheres e as identifica com a dor pelo amor de um homem, objetificando-as? Woolf (2002, p.243) tem razão quando fala que uma "breast surgery is not exactly a clitoridectomy. It is only half a clitoridectomy!" Ainda que, no caso das cirurgias acima citadas, todas as mulheres tenham optado por vontade própria pela operação, quão diferente elas são 
de Iracema na suas apropriações pelo discurso patriarcal do homem virilizado e machista nacional? Pelo que parece, a cirurgia de aumento de seio tem como objetivo tornar a mulher mais desejável para os namorados e maridos atuais ou em potencial. Assim como só são desejáveis e só se casam as mulheres mulçumanas que estiverem circuncizadas. Da mesma forma que a mutilação genital, a prótese de silicone também foi trivializada principalmente pelo discurso da liberdade feminina, sem perceber o quanto elas ainda estão inseridas numa sociedade em que a mutilação sexual fala sobre a interpelação feminina 'in the beauty blacklash', com a esperança de virem a ser amadas e desejadas/colonizadas pelos homens (WOOLF, 2002).

Se a civilização, como disse Freud, se fez na contenção da libido humana, será, por sua vez, a libido feminina aquela que vai ser reprimida, já que falamos de uma sociedade que incentiva a virilidade, a conquista, o prazer e o desejo masculinos como civilização (WOOLF, 2002, p.248)? No caso brasileiro, trata-se de pensar os estereótipos femininos do país que reafirmam o nacionalismo como uma hierarquia de gêneros (MCCLINTON, 1995, p.385), em que a dor e o sofrimento femininos são reforçados pela própria aceitação 'livre' das mulheres no seu desejo de ser desejada custe o que custar, inclusive sacrificando a sua própria vida (IRIGARAY, 2007, p.96). É possível amar diferente? Já se sabe que é preciso criar e originar novas representações femininas em que a maternidade, o sofrimento e a luta pela beleza e o amor do homem não sejam valores centrais das vidas das mulheres. Porém, na declarada pseudo-neutralidade das tradições do país do prazer, é possível criticar a colonização das mulheres? Cada vez que o estereótipo é questionado, uma mulher torna-se tudo aquilo que pode denegrir e culpar a sua 'essência', tornando-se, então, frígida, lésbica, histérica, oferecida, prostituta e afins. Voltando ao exemplo de Cristiana, o seu exterior masculinizado vai ser reflexo de uma personagem cuja subjetividade se revelará agressiva, mau-caráter e desumana (RISSATO, 2011), nada comparado com a docilidade da 'mulher brasileira'. Cristiana, por sua vez, tem que lidar com a crítica e a preocupação das pessoas em relação à sua aparência, pois, antes de ser atriz, ela é mulher. Conforme fala Wolf, enquanto uma mulher não puder se preocupar menos com a aparência da mesma maneira como fazem os homens ou enquanto uma mulher não fizer menos sacrifícios pela imagem ideal como não fazem os homens, as mulheres não poderão vivenciar um status mais igualitário na sociedade (WOLF, 2002, p.189). Enquanto um imaginário de beleza e sacrifícios for reforçar o senso 'feminino' de inferioridade social, o lugar dos homens e das mulheres na sociedade brasileira será diferente e a hierarquia mitológica da nação continuará operando e se apropriando dos corpos, da subjetividade e do erótico femininos.

\section{Considerações finais}

Se o Brasil, enquanto nação, parece uma localização geográfica e imaginária na qual se pensa uma quantidade infinita de zonas sexuais, sofrendo, como país, da visão eurocêntrica colonial e mitológica de terra nova e primitiva a ser desvirginada, seriam as mulheres brasileiras aquelas que mais estariam implicadas neste processo que coloca o Brasil como uma nação do prazer. Tal problema de gênero se mantém não apenas porque as mulheres estão duplamente colonizadas, porque mulheres e porque brasileiras, mas porque tiveram um papel transhistórico e fixo para a definição da masculinidade universal, fosse antes do homem-europeu-colonizador e, mais tarde, do próprio homem-nativo-brasileiro. As brasileiras parecem nunca deixar de ser metaforicamente mitificadas como terra vazia, patrimônio da violência masculina a serem descobertas e apropriadas. Na verdade, aquilo que parece ser observado na cultura midiática das representações das mulheres no país é uma reafirmação da essência feminina nacional que nada tem de natural, mas é fruto de sofrimento e sacrifícios físicos e psicológicos. A dificuldade, assim, continua, já que o desejo das mulheres é interpelado e mediado pelos imaginários nacionalistas das nativas indianistas com a ajuda onipotente da mídia na divulgação da feminilidade 'natural', 'espontânea' e 'solícita' da 'brasileira', condição que não é um elemento predado, mas que, na sociedade nacional e internacional, ainda caracteriza o que é ser mulher no/do Brasil.

Se nações e nacionalismos são construções imaginárias, históricas e políticas de ideologias compartilhadas por uma determinada comunidade (ANDERSON, 2007, p.12), como pensar na mitologia tradicional da essência feminina brasileira e romper com a condição de commodities das mulheres dentro da cultura do país? Como pensar um Brasil de fato mais moderno (ou será 'justo' a palavra correta?) se ainda hoje a sua identidade nacionalista defende uma (pseudo)neutralidade da subjetividade colonizada das mulheres dentro do discurso do patriarcado? Como, de fato, permitir um país para todos no âmbito sexual e das diferenças de gênero, fora do lugar fixo que determinou a posição inferior das brasileiras? Se não entendermos com a ajuda dos discursos pós-modernos que não há calcificação e representação do feminino 
que não seja parcial ou factícia, as mulheres continuarão sem história, sem resistir e sem poder escrever seus próprios desejos e mitos imaginários, permanecendo subordinadas ao homem, à nação e aos sofrimentos artificiais, sacrificando suas vidas, suas almas e seus corpos pelo prazer e diversão definidos na dinâmica econômica de liderança masculina. Se não pensarmos a mitologia indianista a partir de uma análise da teoria de gênero, o imaginário brasileiro continuará a ser depósito das esperanças, aspirações e privilégios masculinos (MCCLINTOCK, 1995, p.385). Sempre incompletas, inferiores, vazias, faltosas, as mulheres continuarão a sofrer. E nenhuma dor será suficiente para se conseguir ser, sentir e amar por si próprias. $\mathrm{Ou}$, como diria Beauvoir, apenas quando for possível às mulheres amarem com a "sua força e não com a sua fraqueza, não para se demitir, mas para se afirmar, então aí o amor tornar-se-á (...) uma fonte de vida e não um perigo mortal (LANCELIN \& LEMONNIER, 2010)". Sem uma crítica aos mitos do nacionalismo brasileiro, a hierarquia de gêneros permanecerá. E o essencial das mulheres, na nação do prazer, continuará sendo muito visível para os olhos. Do desejo dos homens.

\section{Referências}

ALENCAR, José de. Iracema. Rio de Janeiro: Rocco, 2007.

ANDERSON, Benedict. Imagined communities. New York: Verso, 2007.

BAlZAC, Honoré de. A mulher de Trinta Anos. São Paulo: Editora Martin Claret, 1998.

COSTA, Jurandir Freire. Sem fraude nem favor: estudos sobre o amor romântico. Rio de Janeiro: Rocco, 1998.

HOUELLEBECQ, Michel. Estensione del domínio della lotta. Bologna: Edizione Tascabili Bompiani, 2009.

IRIGARAY, Luce. Je, Tu, Nous. New York: Routledge, 2007.

This sex with is not one. New York: Cornell University, 1985.

KUNDERA, Milan. A insustentável leveza do ser. Rio de Janeiro: Cia de Bolso, 2008.
LACAN, Jacques. On feminine sexuality, the limits of love and knowledge, 1972-1973. New York: Norton \& Company, 1975.

LANCELIN, Aude; LEMONNIER, Marie. Os filósofos e o amor. Lisboa: Tinta da China, 2010.

MARTHE, Marcelo. A Nação do prazer. Revista Veja, Edição 30 de março, p. 130 - 133, 2011.

McCLINTOCK, Anne. Imperial Leather. New York: Routledge, 1995.

NAGEL, Joane. Race, Ethnicity and Sexuality. New York: Oxford Press, 2003.

PLATÃO. O Banquete. Lisboa: Edições 70, s/d.

PONDÉ. Luiz Filipe. Nós, os ptrodátilos. Folha de São Paulo, s/p, Edição 11 de abril, 2011.

RISSATO, Laís. Cristiana Oliveira: 'Magreza não é virtude'. Revista Quem, s/p, Edição 30 de março, 2011. [Disponível em: http://revistaquem.globo.com/Revista/Quem/0,EMI22 2241-9531,00.html]

ROSE, Jacqueline; MITCHELL, Juliet. Feminine Sexuality: Lacan and the école freudienne. New York: Norton and Pantheon Books, 1985.

SOLER, Colette. O que Lacan dizia das mulheres. Rio de Janeiro: Jorge Zahar Ed., 2005.

WOOLF, Naomi. The beauty Myth. New York: Harper Perenial, 2002.

ZIZEK, Slavoj. How to read Lacan. New York: Norton \& Company, 2007.

Recebido em 08 de maio de 2010. Aceito em 07 de novembro de 2011. 